\title{
SEMINÁRIO \\ “TÉCNICAS TRADICIONAIS DE CONSTRUÇÃO DE ALVENARIA E SEU USO NA CONSERVAÇÃO DE EDIFÍCIOS HISTÓRICOS: OBJETIVOS E ASPIRAÇÕES”
}

I8 A 22 DE AGOSTO DE 2003, NO EDIFÍCIO VILA PENTEADO, COM A PARTICIPAÇÃO DO PROF. DR. JOÃO CARLOS DE OLIVEIRA MASCARENHAS MATEUS ${ }^{1}$

\section{Beatriz Mugayar Kühl \\ Maria Lucia Bressan Pinheiro}

\begin{abstract}
"Nós podemos viver sem a arquitetura, e adorar sem ela, mas não podemos rememorar sem ela. Como é fria a história, como é inanimada toda imagem, comparada àquela que a nação viva escreve, e que o mármore incorruptível ostenta! Quantas páginas de registros duvidosos nós poderíamos dispensar, por algumas pedras colocadas umas sobre as outras!." (John Ruskin)
\end{abstract}

"Para bem restaurar é necessário amar e entender o monumento, seja estátua, quadro ou edifício, sobre o qual se trabalha." (Camillo Boito)

"A restauração constitui o momento metodológico do reconhecimento da obra de arte, na sua consistência física e na sua dúplice polaridade estética e histórica, com vistas à sua transmissão para o futuro." (Cesare Brandi).

A questão da preservação do patrimônio arquitetônico é central para a atividade do arquiteto na atualidade. Tal fato decorre das profundas alterações que se têm verificado nesse campo, com uma significativa e crescente ampliação daquilo que é considerado bem de interesse para a preservação, não mais restrito a monumentos isolados, unanimamente considerados de excepcional valor histórico e artístico, mas incluindo também grandes conjuntos arquitetônicos ou ambientes urbanos inteiros, pertencentes aos mais variados períodos da história.

Nesse sentido, a linha de pesquisa em História e Preservação da Arquitetura Brasileira, parte da recém-instituída área de concentração de pós-graduação em História e Fundamentos da Arquitetura e do Urbanismo, tem por objetivo, de um lado, a compreensão da problemática da arquitetura brasileira atual, pela revisão crítica de nosso legado arquitetônico, e, de outro lado, contribuir para a 
(1) Engenheiro civil formado pelo Instituto

Técnico Superior de Lisboa, com

especialização e mestrado em ciências da arquitetura, conservação de monumentos e sítios históricos, no R. Lemaire Center for Conservation da Katholieke Universiteit Leuven (KUL), Bélgica, e doutorado em engenharia civil, Instituto Superior Técnico (IST), Lisboa. De 1993 a 1995 trabalhou como assistente na KUL no desenvolvimento $\mathrm{e}$

assessoria da coordenação do projeto financiado pela União Européia, "Um sistema de peritagem para a

avaliação da deterioração em antigas alvenarias de tijolo", em colaboração com o TNO-Bouw (NL), a Technische Universität de Hamburg-Harburg (D) e o Politecnico di Milano (I).

Atualmente é consultor da vereadora responsável pelos pelouros do licenciamento urbano e reabilitação urbana da Câmara Municipal de Lisboa, devendo definir estratégias de conservação da unidade da rua de $S$. Bento elaborar levantamento do estado de conservação da baixa pombalina. É Cultor della materia do curso

"Técnicas de restauro arquitetônico da licenciatura em gestão de processos construtivos",

Faculdade de Arquitetura, Universidade La Sapienza, em Roma (Responsável: professor Maurizio Berti), e diretor de projeto execução das intervenções de conservação do Instituto Português de S. António e do Colégio Pontifício Português, ambos em Roma. Acabou de publicar sua tese de doutorado sobre o tema específico do seminário, intitulada Técnicas tradicionais de construção de alvenarias. A literatura técnica de 1750 e 1900 e o seu contributo para conservação de edifícios históricos. Lisboa: Horizonte, 2002. preservação efetiva deste. Considera-se que a ação preservacionista - isto é, aquela que visa à transmissão do bem cultural às gerações futuras - só pode ser levada a cabo de forma efetiva, se estiver baseada em conhecimento sólido do objeto de intervenção (o edifício), tanto em sua dimensão estético/formal e simbólica como em sua materialidade intrínseca. É imprescindível, portanto, o estabelecimento de critérios valorativos válidos e de procedimentos de conservação e/ou restauração, visando não apenas à manutenção da integridade física do bem cultural, mas também o respeito por suas características arquitetônicas. 0 seminário "Técnicas tradicionais de construção de alvenaria e seu uso na conservação de edifícios históricos", desenvolvido na pós-graduação da FAUUSP, entre os dias 18 e 22 de agosto de 2003, insere-se nos esforços voltados a esta problemática, os quais têm sido empreendidos pela disciplina AUH-5816 Metodologia e Prática da Reabilitação Urbanística e Arquitetônica, pioneiramente criada pelo Prof. Dr. Benedito Lima de Toledo no programa de pós-graduação da Faculdade de Arquitetura e Urbanismo da Universidade de São Paulo, a que procuramos dar seqüência na disciplina AUH-5852 - Técnicas Construtivas Tradicionais, de nossa responsabilidade. De fato, o evento foi parte integrante do quadro de atividades dessa disciplina, no presente semestre, contando com o apoio e o patrocínio de variados organismos: Comissão de Cooperação Internacional/USP; Comissão de Pós-Graduação FAUUSP; Fundação Casa de Rui Barbosa, RJ; Fundação Vitae; Instituto Português de Santo António, Roma.

A fim de oferecer uma contribuição para a análise da relação entre arquitetura e técnicas construtivas em geral, por meio do exame da tratadística dos séculos 18 e 19, o seminário tratou especificamente da constituição e restauração das alvenarias tradicionais, tema pouco explorado em nosso meio, porém essencial para promover intervenções responsáveis no patrimônio construído. Aberto pelo Prof. Dr. Benedito Lima de Toledo, com palestra sobre questões conceituais relacionadas à preservação de bens culturais, o evento foi estruturado por um ciclo de palestras a cargo do dr. João Mascarenhas Mateus, especialista em alvenarias históricas (V. currículo anexo), debates, e uma mesaredonda final sobre casos de estudos de edifícios que abrigam coleções, com a participação adicional da professora Griselda Klüppel, do Museu de Arte Sacra da UFBA e da arquiteta Cláudia Carvalho, responsável pela Casa de Rui Barbosa, no Rio de Janeiro.

A primeira fase do ciclo de palestras ministradas pelo dr. João Mascarenhas Mateus foi inteiramente voltada à aquisição de conhecimentos básicos sobre as alvenarias e questões relacionadas ao emprego de técnicas construtivas tradicionais e seu uso na restauração, visando estabelecer uma base de diálogo comum entre seu público-alvo: arquitetos e engenheiros, mas também historiadores, conservadores, restauradores etc., com interesse na área de preservação de edifícios e/ou por trabalharem com coleções abrigadas em construções históricas. Mais especificamente, foram abordados os seguintes 
aspectos: concepção e dimensionamento de edifícios de alvenaria tradicional; o uso da pedra e do tijolo na literatura técnica de 1750 a 1900; concepção e dimensionamento de edifícios; material das alvenarias - fabricação, preparação, composição; execução e detalhes de proteção de edifícios de alvenaria tradicional; revisão bibliográfica. Especial atenção foi dedicada à delicada questão da (in)compatibilidade entre materiais e técnicas tradicionais e os materiais contemporâneos, comumente empregados na construção civil, principalmente quanto à necessidade de "transpiração" das alvenarias históricas. Também foi discutida a pertinência de uma postura cautelosa diante das novas técnicas e materiais desenvolvidos, especificamente, para o restauro de edificações tradicionais, cujas implicações, a longo prazo, podem não ser ainda conhecidas e testadas, além de estarem sujeitas a alterações imprevistas de formulação - o que pode gerar conseqüências catastróficas para os bens culturais a serem preservados.

Os casos de estudo, apresentados na mesa-redonda final, tinham em comum o fato de tratar de edifícios de interesse histórico contendo coleções. 0 dr. Mascarenhas apresentou um projeto de transformação de um edifício geminado de habitação em Roma, de origem medieval, de alvenaria de tijolos e partes de pedra, em espaço expositivo do Instituto Português de Santo António, analisando possibilidades e limites do emprego de técnicas tradicionais de construção em uma obra de restauro. Cláudia Carvalho apresentou os problemas de manutenção e conservação relacionados à Casa de Rui Barbosa, construção oitocentista de alvenaria de tijolos, construída isolada em meio a um jardim, abrigando uma coleção de objetos de natureza variada: o acervo pessoal de Rui Barbosa. Já o Museu de Arte Sacra de Salvador, abordado por Griselda Klüppel, é o antigo convento carmelita da cidade, construção do século 17, em alvenaria de pedra, transformada em museu, em meados do século passado, contendo valiosíssima coleção de objetos sacros confeccionados com vários materiais. Assim, os edifícios diferiam muitíssimo entre si, por sua configuração e implantação, pelas condições climáticas a que estão sujeitos, pelos sistemas construtivos adotados, pelas patologias presentes, e pelo próprio tipo de coleções que abrigam, enriquecendo o debate sobre o assunto.

Essa rica casuística ofereceu um panorama amplo de problemas e das variadas formas de soluções propostas para enfrentá-los. Ficou claro, porém, a semelhança do método de trabalho e da unidade de princípios perseguidos nos três trabalhos, destacando-se aí os princípios de reversibilidade, distinguibilidade e mínima intervenção, consagrados pelas cartas patrimoniais. Evidenciou-se, assim, uma questão de extrema importância no que se refere à preservação: a unidade metodológica, mesmo na diversidade dos meios a serem empregados para enfrentar situações as quais sempre variam muitíssimo na prática. Outro ponto essencial abordado, de maneira similar e com extrema sensibilidade por parte dos expositores, é a necessidade de trabalhar-se articuladamente, pensando 
de modo concomitante o edifício, que, em si, é uma obra de arte, e a coleção de arte que deve abrigar, pois escolhas devem ser feitas, de modo a harmonizar a preservação de ambos. Não podem ser tomadas decisões, nem em detrimento de um, nem a despeito do outro, porque se trata de bens culturais, de objetos nãorepetíveis de valor histórico e estético, que devem ser transmitidos ao futuro da melhor maneira possível, tratando-se, portanto, de trabalho de extrema responsabilidade.

O seminário teve, então, o intuito de estabelecer um primeiro contato entre vários profissionais da área, ampliando a discussão e o intercâmbio de experiências sobre o assunto, dentro do país e com o exterior, como um meio de propiciar um diálogo mais esclarecido e enriquecedor. Pretende-se realizar programas semelhantes vinculados aos ciclos bienais da disciplina AUH-5852, sempre com acentuado caráter interdisciplinar. Nossa aspiração é a de o evento constituir o ponto inicial de um programa duradouro de formação, atualização e intercâmbio entre profissionais da área, e que esses laços se fortaleçam, frutifiquem e constituam a base para futuros intercâmbios.

\section{Beatriz Mugayar Kühl}

Professoras do Departamento de História da Arquitetura e Estética do Projeto, orientadoras no curso de Pós-Graduação da FAUUSP e coordenadoras do Seminário "Técnicas tradicionais de construção de alvenaria e seu uso na conservação de edifícios históricos: Objetivos e aspirações". 